Int. J. Electrochem. Sci., 11 (2016) 8950 - 8963

\title{
Protection of Corrosion of Carbon Steel with Core-Shell Inorganic Magnetic Nanogels in Formation Water
}

\author{
A.S.Fouda ${ }^{1, *}$, H.Megahed $^{2}$, Z. M. Mohamed ${ }^{3}$, M. Shaker $^{3}$ \\ ${ }^{1}$ Department of Chemistry, Faculty of Science, El-Mansoura University, El-Mansoura-35516, Egypt, \\ ${ }^{2}$ Department of Chemistry, Faculty of Science, Benha University, Benha Egypt \\ ${ }^{3}$ Egyptian General petroleum corporation, Egypt \\ *E-mail: asfouda@mans.edu.eg
}

doi: $10.20964 / 2016.11 .57$

Received: 16 June 2016 / Accepted: 28 August 2016 / Published: 10 October 2016

The effectiveness of poly (2-acrylamido-2-methylpropane sulfonic acid) (PAMPS) and copolymers with acrylic acid (AA) and acrylamide (AM) magnetic nanogels as protective corrosion of CS in reaction with water by (EIS), (EFM) and tafel polarization method. Polarization method demonstrated that all the polymers are mixed inhibitor type. (EIS) Electrochemical impedance given that the attendance of these investigated polymers declines the double layer capacitance and improvement the charge transfer resistance. The polymers adsorption on surface of steel was follow isotherm Temkin. The morphology of the CS surface was examining by (EDX) energy dispersive X-ray and (SEM) scanning electron microscope. The data obtain showed improvement in efficiencies for inhibition with raising the dose of inhibitor.

Keywords: CS, Corrosion inhibition, Magnetite core-shell nanogel polymers, Formation water, SEM, EIS, EFM.

\section{$\underline{\text { FULL TEXT }}$}

(C) 2016 The Authors. Published by ESG (www.electrochemsci.org). This article is an open access article distributed under the terms and conditions of the Creative Commons Attribution license (http://creativecommons.org/licenses/by/4.0/). 